\title{
A HOLISTIC APPROACH TO GENERAL AVIATION AIRCRAFT STRUCTURAL FAILURE PREVENTION IN AUSTRALIA
}

\author{
Kyriakos I. Kourousis \\ School of Aerospace, Mechanical and Manufacturing Engineering, RMIT University, \\ Melbourne, Australia \\ E-mail: kyriakos.kourousis@rmit.edu.au
}

Received 29 January 2013; accepted 08 May 2013

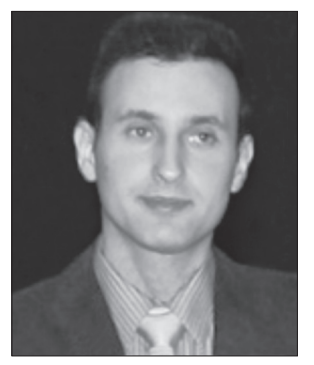

\begin{abstract}
Kyriakos I. KOUROUSIS, PhD, CEng.
Education: BS Aeronautical Engineering, Hellenic Air Force Academy, Greece, 2000. MS Computational Mechanics (Solids), National Technical University of Athens, Greece, 2003. PhD Solid Mechanics (Metal Plasticity),

National Technical University of Athens, Greece, 2011.

Affiliations and functions: 2012 to present: Lecturer in Aerospace and Aviation, RMIT University, School of Aerospace, Mechanical and Manufacturing

Engineering.

Research interests: Airworthiness, aircraft maintenance, aviation safety, defense engineering, solid mechanics, material constitutive modeling, cyclic plasticity. Publications: Author of 4 journal papers, 1 book chapter and 4 conference paperspresentations.
\end{abstract}

\begin{abstract}
Ageing aircraft are becoming a major issue in the general aviation (GA) industry, both in terms of safety and maintenance and support cost. Ensuring a sound structure is considered one of the primary challenges in this area, it is, therefore, attracting the attention of the regulating authorities. The Civil Aviation Safety Agency (CASA) has taken a mixture of actions to tackle the various issues related to the diverse Australian GA ageing aircraft fleet. Further efforts focus on increasing the awareness of the different parties engaged in aircraft operations, maintenance and design, as well as quantification of the associated risk. In this frame a holistic approach is proposed to cover the various aspects, emphasizing the use of cost-effective structural health monitoring (SHM) systems and web-based education and information dissemination on ageing aircraft issues.
\end{abstract}

Keywords: ageing aircraft, general aviation, structural health monitoring, fatigue, corrosion.

\section{Introduction}

The integrity of the aircraft structure (airframe) is recognised as the primary source of concern for an ageing general aviation (GA) aircraft, in terms of criticality (flight safety) and the associated replacement, restoration, and repair cost for maintaining airworthiness. While other critical systems may face challenges of the same magnitude, these can be addressed more easily and less expensively compared to the primary structure issues. For example, ageing components of a hydraulic, or an electrical system, may be overhauled or even replaced without affecting the economical life of the aircraft (reasonable cost), but in the case of overhauling and re-furbishing an aircraft wing it would require a non-manageable cost for most of the low-end users of GA (taking into account the market value of a 30 or 40 years old aircraft).

The most significant post-manufacturing ageing factors identified are fatigue and corrosion (Wahab et al. 2004), as well as deterioration of mechanical/ electrical systems, driven mainly by the way aircraft are operated and maintained (including storage). By definition, ageing aircraft are operated far beyond their design life, and in most cases in ways that deviate significantly from the load spectrum and environment assumed in the original design. In terms of airframe airworthiness, the severity of their impact may be assessed by estimating the accumulated damage and corrosion, 
which in turn requires the recurrent collection, analysis and interpretation of actual usage data, compared to the assumed (design) usage.

\section{Background}

The United States Federal Aviation Authority (FAA) has taken several initiatives on GA aircraft structural fatigue monitoring and management, through collaborative research and development programs between the industry and academia (e.g. Embry-Riddle, University of Texas at San Antonio), mainly focused on the collection of real-life usage data from GA aircraft fleets with the use of on-board sensors and data recording systems (FAA 1994; FAA 2001a; FAA 2001b; FAA 2001c; FAA 2006). These projects, some of them still in progress or under evolution, have led to the development of methods and equipment capable of acquiring, collecting and analysing flight load data (e.g. the Airframe Cumulative Fatigue Monitoring System - FAA 1994), as well as calculating the structural fatigue in GA aircraft structures (wing, fuselage, empennage, landing gear) through a probabilistic safe life approach (Ocampo, Millwater 2010; Ocampo et al. 2011; Kulyk et al. 2011). Also, some other low-cost technological devices (fatigue monitoring systems) have been developed in an effort to capture the GA aircraft market (e.g. the TL Electronic TL-4324 Fatiguemeter and the TL-5824 Structural Life Monitoring Unit (Marczi et al. 2004), which is depicted in figure 1).

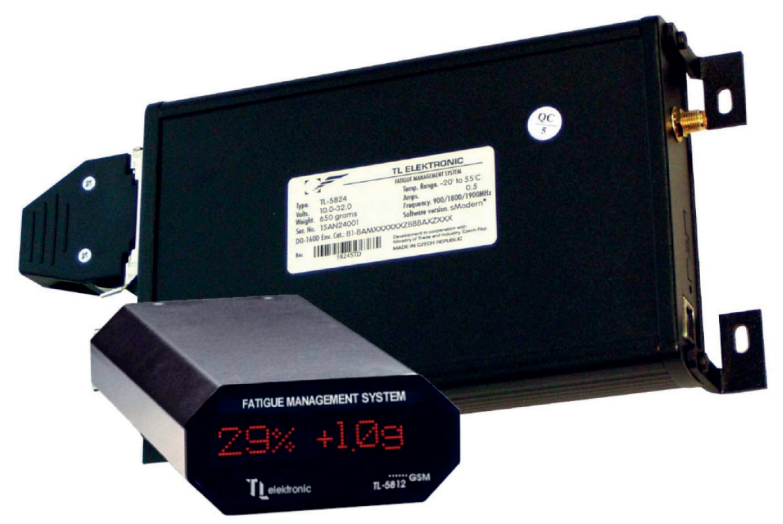

Fig. 1. TL Electroniks TL-5824 Fatigue-meter unit

In the field of corrosion sensing and monitoring of aircraft structures various techniques, such as guided waves, electrical impedance measurement, Fiber Bragg grating, etc. are under development and validation, aiming at a corrosion prone airframe. To this end, technological applications with potential usage on GA aircraft have emerged (e.g. corrosivity sensors/MEMS; Fig. 2). Nevertheless, these techniques and systems at present provide an indication of the probability of corrosion on the structure, thus there is a necessity for further verification of their effectiveness, through visual inspection and quantification of the corrosion extent (Amos 2009).

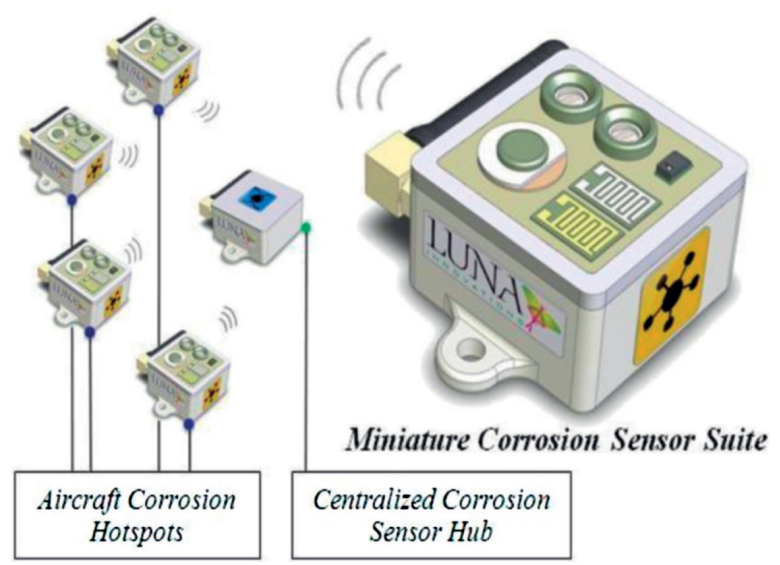

Fig. 2. Luna smart environmental corrosivity sensor suite for aircraft applications (LUNA 2013)

Moreover, FAA has also recognized the issue of realistic usage data collection and estimation of the accumulated structural damage, as an effective way to increase the awareness of the GA aircraft owners, operators and maintainers. Thus, parallel activities have been taken to educate and train people involved in GA aircraft operation and maintenance (FAA 2006) through a website developed, hosted and maintained by Wichita State University's National Institute for Aviation Research (under the supervision of the FAA) (Aging ... 2012).

\section{Current state in Australia and safety implications}

At present, neither the aircraft users, nor the Regulating Authorities have adopted any of these structural health monitoring systems (SHM) and methodologies to tackle the existing ageing GA aircraft issues. Focusing on the Australian GA aircraft, it is noted that no onboard SHM systems are used to monitor structural fatigue and corrosion. Therefore, it is evident that progress has to be made in this field, through research and development projects, in order for the users and the Regulators to gain the necessary level of confidence about the capabilities, advantages and feasibility of these systems. This in turn is expected to assist the Regulators to introduce a set of minimum requirements, enabling that way a homogenised approach across the GA industry.

The Australian Civil Aviation Safety Authority (CASA) has recently published a Discussion Paper (CASA 2012b) regarding the findings of the Stage 2 of the Ageing Aircraft Management Plan (AAMP) (CASA 2012a), as well as seeking the aviation industry views and opinions on further actions to be taken. The AAMP is applicable to the GA aircraft (excluding the powerplant), covering the ageing issues affecting the structural integrity and condition of the airframe parts, as well as the mechanical and electrical systems. This Discussion Paper provides five principal (guideline) options for further actions (CASA 2012b):

Option 1. Do nothing: 
This is considered not to be a realistic option, since it has been recognized that there is a high risk in taking no further actions to look into the ageing aircraft related issues;

Option 2. Matrix Tool:

A prototype Matrix Tool was deployed on-line (CASA... 2012a) for use by the registered operators, as a way to enhance their awareness on their aircraft ageing status. This is considered to be a generic risk assessment web-based tool. The primary focus was on testing the functionality and user-friendliness of this web-based tool. CASA proposed further development of the prototype Matrix Tool into a production version capable of accurately predicting the likelihood of the ageing status of an aircraft. This is going to be used by the registered operators, as soon as it becomes available on-line on the CASA website;

Option 3. E-Learning:

An E-Learning Course was developed and introduced by CASA (CASA... 2012b) for use by registered operators, as a first step to enhance their understanding of ageing related issues (fatigue, ageing science, etc.). CASA proposed further promotion and encouragement of the use of this E-Learning Course to improve the operators' knowledge, so as to equip them better to manage their aircraft in relation to ageing issues;

Option 4. Type Clubs:

CASA proposed the encouragement of the participation and formation of Type Clubs where members are able to collectively share their knowledge and experience in the support of their ageing aircraft. This might include the ability to amortise any costs associated with the development of maintenance standards and schedules for ageing aircraft and/or supplementary type certificates.

Option 5. Professional Development:

CASA proposed the development and delivery of professional development training to licensed aircraft maintenance engineers (LAMEs) and aeronautical engineers to ensure enhanced systems of maintenance outcomes that genuinely address all aspects of the ageing process in the Australian operating and maintenance environment.

\section{An integrated approach to prevent engineering failures}

\subsection{Structural health monitoring systems (SHM) for GA aircraft}

\subsubsection{SHM system outline}

As clearly recognised by CASA (CASA 2012b) taking no further action in the AAMP bares a significant risk for the GA industry. The use of SHM systems is considered to be a reliable way to collect realistic usage and environmental data and further assess and monitor the struc- tural damage accumulation/life consumption of ageing aircraft. Thus, any mitigation action (currently in place or under development) would probably have to include a SHM aspect and not rely solely on data collection methods that have very low reliability (e.g. questionnaire surveys). In fact, unreliable data and analyses may lead to decisions that:

- have a negative impact on aviation safety, due to the limited knowledge/awareness on the Australian ageing GA aircraft usage conditions/patterns (e.g. load spectrum, continent-wide environmental conditions, etc.), and/or;

- impose unnecessary economical burden to the users, if a conservative approach is adopted as a measure to control risk (e.g. extensive and frequent preventive maintenance).

The production version of this CASA Matrix Tool is thought to have improved capabilities in predicting more accurately the ageing status of an aircraft (CASA... 2012b). This tool, fed with operational and maintenance details provided by the operators, outputted a very rough indication of the ageing status of their aircraft (generic risk assessment). Nevertheless, if the capture of accurate usage data relies solely on the minimal and subjective information provided by the operator, then it is deemed that even the production version will not be as effective as expected. The development of an accurate (production version) Matrix Tool requires that CASA would gain access to a representative actual usage dataset. This dataset can be collected through a research program covering flight data load surveys, environmental data surveys and complementary questionnaire surveys. In particular, with reference to the prototype Matrix Tool, the following data can be collected through this program: flight hours per year, sector altitude and length, number of landings per flight hour, runway operations (operational aspect) and flight and storage environment, washing type and frequency (environmental aspects).

In addition, this program shall be able to investigate the feasibility of adopting technologically based methods for the collection, calculation and assessment of the structural fatigue and corrosion accumulation in ageing GA aircraft structures. This can be facilitated through the in-use evaluation and validation of the effectiveness of systems currently offered in the market (or experimental devices already developed), either as integrated ready-to-use solutions (e.g. fatiguemeters for GA aircraft) or stand-alone components or devices (e.g. MEMS for corrosion monitoring, corrosivity sensors, etc.). The state of the art fatigue and corrosion calculation methods shall be assessed as well, in view of developing a comprehensive yet simple method to appropriately meet the specific requirements of the GA domain (fleet diversity, limited resources, etc.). 
The basic requirement for a GA aircraft SHM system is to employ a low-budget technical solution capable of addressing the primary issues affecting continuing airworthiness in a simple, yet effective way. Thus, one has to take into account the operationally and environmentally related factors having the most significant impact on the integrity of the airframe, which are: flight loads (load spectrum), corrosion and discrete events (e.g. hard landings). The proposed SHM approach aims to cover these factors through an integrated approach (Fig. 3).

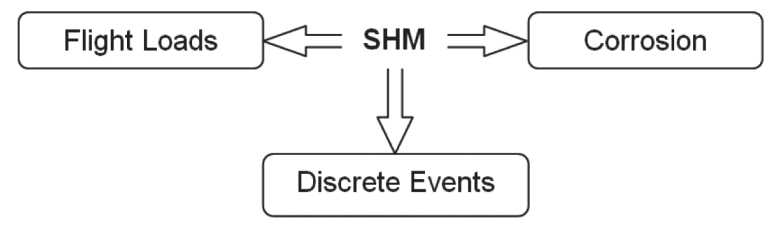

Fig. 3. Structurally and environmentally significant factors covered by the proposed SHM approach

In brief, the sought (optimum) solution is a single SHM unit encompassing a set of data acquisition sensors (for loads, corrosion, discrete events) and a data storage device, permitting the retrieval and post-processing with the use of dedicated PC software. In addition, the SHM system should have the following characteristics in order to address the GA industry diverse environment:

- minimal interference with the aircraft structure/ systems/instruments/etc. (e.g. no structural modification needed, powered by self-contained battery);

- applicability to different aircraft types and versions (e.g. simple calibration);

- user-friendliness for the aircraft operator and the supporting engineer.

The hardware of the proposed SHM system shall exploit emerging technology that has recently become commercially available. The ultimate objective of this system would be to evaluate the functionality, applicability and effectiveness of the offered technological solutions against the ageing aircraft management guidelines set by the regulators.

\subsubsection{Fatigue and corrosion monitoring}

Further to the assessment of the risks associated to GA aircraft ageing, mitigation options need to be assessed as well. In this regard, it is deemed necessary to investigate the feasibility of adopting technologically based methods for the collection, calculation and assessment of the structural fatigue and corrosion accumulation in ageing GA aircraft structures. This involves the:

- in-use evaluation and validation of the effectiveness of systems currently offered in the market (or experimental devices already developed), either as integrated Commercial Of-The-Shelf
(COTS) solutions (e.g. fatiguemeters for GA aircraft) or stand-alone components/ devices;

- the assessment of the state of the art fatigue and corrosion calculation methods, in view of developing a comprehensive yet simple method to appropriately meet the specific requirements of the GA domain (fleet diversity, limited resources, etc.);

- the use of these systems in various aircraft, fleets and places around the continent, in order to collect representative data reflecting the in-country use of GA aircraft (flight operations and environmental conditions).

Moreover, the research is capable to provide the basis for the development of a high-tech product that would cover successfully the indigenous industry specific needs, relevant to the Australian operational and environmental conditions.

\subsubsection{Decision making - maintenance on demand}

Fatigue and corrosion monitoring technological systems are able to provide the aircraft owners with the necessary decision making tool for improved safety management, as well as optimised operational usage, maintenance and storage of their ageing aircraft. In this regard, the individual and fleet-wide aircraft tracking of fatigue and corrosion is expected to reduce the overall operating cost of the ageing GA aircraft by increasing the awareness of the owners on the operational and storage factors which have direct (negative) impact on maintenance and repair cost.

A SHM system shall provide a direct indication to the operator on the actual usage of the aircraft and the corresponding damage accumulated due to fatigue, corrosion and discrete events. Therefore, the continuing airworthiness of the aircraft can be enhanced through adopting a proactive response - maintenance on demand approach (inspections, preventive maintenance tasks, application of rotation schemes in fleets, etc.). In particular, the SHM system will allow the optimisation of the inspection intervals (both in terms of safety and economy), which are currently calculated on the designer's initial assumptions for most of the ageing GA aircraft.

The adoption of these technological solutions adds an extra safety feature to an ageing airframe (less probable structural failures), thus this would potentially allow the owners to negotiate with the aviation insurance companies their individual-optimum level of insurance premium.

In summary, a SHM system for GA is expected to:

- assist the regulators in the development of the production version of the Matrix Tool by providing realistic operational usage and environmental data of ageing GA aircraft; 
- identify possible unique ageing issues related to the aircraft usage and environmental factors in the continent;

- allow CASA to conduct a risk assessment of the Australian operated GA aircraft structural issues in support of policy decisions, based on its findings;

- act as the basis for the development (design and manufacturing) of a series of technologically advanced products, capable of covering the specific needs of the indigenous aviation industry;

- optimise the GA ageing aircraft insurance policies, by providing a means to determine the appropriate, for each case of aircraft, level of premiums.

\subsection{Information dissemination and education on ageing GA aircraft issues}

\subsubsection{Ageing aircraft web-portal}

CASA has recognized the importance of education and information sharing in increasing aircraft operators and maintainers awareness on ageing aircraft related issues. In the frame of the Ageing Aircraft Management Plan (AAMP) several initiatives have been taken by CASA and were proven to be effective in this regard. Nevertheless, since this effort is an ongoing task, the use of web resources, as well as the engagement of specialized knowledge providers is deemed to be necessary in order to ensure nationwide reach and high quality education respectively.

The various tools CASA has deployed and used in the AAMP (Matrix Tool webpage, E-Course webpage, etc.) can be consolidated under a common web-portal for improved accessibility of the information by the target audience (aircraft operators, maintainers, etc.).

In line with Option 2, 3, 4 and 5 of the CASA Discussion Paper (DP) 1205CS (CASA 2012a), a possible solution is to consolidate the existing web pages under a common web-portal. In particular, this could be facilitated through a dedicated ageing GA aircraft web-portal developed, hosted and maintained by an independent organization, such as a research centre or a technical University, under the supervision of CASA.

This web-portal could potentially incorporate the following themes/sources of information/etc.:

- the production version of the Matrix Tool (Option 2), for use by the registered operators, as well as potential aircraft buyers/leasers;

- complete E-Courses (Option 3) on ageing aircraft issues (ageing science, maintenance issues, etc.) particularly covering:

- fundamental education on ageing aircraft issues for registered operators, pilots, LAMEs and the public (e.g. technical training and tertiary education students, etc.);
- Professional Development Courses (Option

5) for LAMEs and aeronautical engineers.

- news from CASA on significant information (service bulletins), major events (e.g. incidents), etc. related to ageing aircraft (with links to the CASA website);

- dissemination of information from Type Clubs activities on ageing aircraft management, etc. (Option 4);

- useful Links from organizations, companies, etc. around the world which deal directly or indirectly with the management of ageing GA aircraft (e.g. FAA, AOPA, etc.).

\subsubsection{Face-to-face educational workshops}

Further education of GA aircraft owners and LAMEs across the continent can be facilitated by educational workshops in each of the different regions. Specific, to each group, workshops can be developed-delivered through the contracting organization (research centre/ University) in consultation with the aviation industry (CASA, CAR35/Part 21.M Authorised Persons, experienced LAMEs, design and maintenance organisations, etc.). This will enable the reduction of the CASA's AAMP education related cost, as well as the workload of CASA's officers.

In summary this program is expected to:

- increase the awareness of the safety implications of ageing GA aircraft among people owning, operating and maintaining these aircraft;

- enable more effective communication among the different parts of the GA community, through a consolidated ageing aircraft web-portal developed, hosted and maintained by an independent organization (research centre/ University);

- reduce CASA's education related costs and workload, through outsourcing the development of the educational workshops.

\section{Conclusions}

A holistic approach is necessary to be applied for confronting the issue of ageing GA aircraft in Australia. Both the diversity of the industry and the safety implications necessitate the use of solutions able to address the associated issues in a cost-effective way. SHM has been applied for long in the high end of aviation, especially military aircraft, providing useful insight into the usage spectrum of aircraft and helping to optimise the maintenance operations relevant to structural integrity airworthiness. The technological advancement in this area is expected to assist in this effort. In addition, the importance of education and information dissemination has been recognized by the regulators as the appropriate way to increase the awareness of the GA community on ageing aircraft is- 
sues. This bi-fold approach needs to be tested in practice, and further on, the findings must be incorporated in a management program supervised by CASA under close collaboration with different industry stakeholders (operators, maintainers, design organizations).

\section{References}

Aging General Aviation Education and Training Website [online]. 2012. [cited 15 December 2012]. Available from Internet: http://www.aginggeneralaviation.org

Amos, J. 2009. Recent advances in inspection and health monitoring of aerospace materials and structures for general aviation, in Seminario Internacional de Inspeccion y Monitoreo de la Sanidad de Materiales y Estructuras Aeronauticos, CIDESI, Mexico [online], [cited 10 December 2012]. Available from Internet: http:// www.cidesi.com/taller_presentaciones/seminario-yay-amos.ppt

CASA. 2012a. Ageing Aircraft Management Plan Stage 2 - Industry Feedback and Awareness [online], [cited 10 January 2013]. Available from Internet: http:// casa.gov.au/wcmswr/_assets/main/lib100074/stage2.pdf

CASA. 2012b. Ageing Aircraft Management Plan: Discussion paper 1205CS [online], [cited 10 January 2013]. Available from Internet: http://casa.gov.au/wcmswr/_assets/main/ lib100097/dp1205cs.pdf

CASA Learning Academy [online]. 2012a [cited 12 December 2012]. Available from Internet: http://casa.learnflex.net/ include/ login.asp?url=/users/index.asp

CASA Protype Matrix Tool [online]. 2012b [cited 10 December 2012]. Available from Internet: http://www.yourplane.com.au

FAA. 1994. DOT/FAA/CT-TN 93/23. Design Manufacture and Test of a Flight Load Recorder for Small Aircraft [online], [cited 15 December 2012]. Available from Internet: http:// www.tc.faa.gov/its/worldpac/techrpt/cttn93-23.pdf

FAA. 2001a. DOT/FAA/AR-00/50. A Methodology to Predict the Empennage In-Flight Loads of a General Aviation Aircraft Using Back Propagation Neural Networks [online], [cited 15 December 2012]. Available from Internet: http:// www.tc.faa.gov/its/worldpac/techrpt/ar00-50.pdf

FAA. 2001b. DOT/FAA/AR-01/44. Statistical Loads Data for Cessna 172 Aircraft Using the Aircraft Cumulative Fatigue System (ACFS) [online], [cited 15 December 2012]. Available from Internet: http://ntl.bts.gov/ lib/18000/18400/18400/ PB2001108661.pdf

FAA. 2001c. DOT/FAA/AR-01/80. Improved Methodology for the Prediction of the Empennage Maneuver In-Flight Loads of a General Aviation Aircraft Using Neural Networks [online], [cited 17 December 2012]. Available from Internet: www.tc.faa.gov/its/ worldpac/ techrpt/ ar01-80.pdf

FAA. 2006. Roadmap for General Aviation Aging Airplane Programs [online], [cited 12 January 2013]. Available from Internet: http://www.faa.gov/aircraft/air_cert/ design_approvals/small_airplanes/cos/aging_aircraft/media/roadmapGAAgingAirplane.pdf

Kulyk, M.; Kucher, O.; Miltsov, V. 2011. Mathematical models of the calculation of aircraft structural reliability, Aviation 15(1): 11-20. http://dx.doi.org/10.3846/16487788.2011.566315

LUNA. 2013. Smart Environmental Corrosivity Sensor Suite for Aircraft Applications [online], [cited 14 January 2013]. Available from Internet: http:// virtualacquisitionshowcase. com/document/1475/briefing

Marczi, T.; Ruzicka, M.; Slavik, S. 2004. Fatigue monitoring and operational safety improvement of small sport planes, in $24^{\text {th }}$ International Congress of the Aeronautical Sciences,
Yokohama, Japan [online], [cited 15 January 2013]. Available from Internet: http:// http://www.icas.org/icas_archive_cd1998-2010/ icas2004/ papers/149.pdf

Ocampo, J.; Millwater, H. 2010. Development of probabilistic stress life curves and probabilistic Miner's damage distribution using fatigue, in Proceedings of Aircraft Airworthiness and Sustainment Conference, USA [online], [cited 10 December 2012]. Available from Internet: http://meetingdata. utcdayton.com/agenda/airworthiness/2010/proceedings/ techpapers/TP3214.pdf

Ocampo, J.; Millwater, H.; Singh, H., et al. 2011. Development of a probabilistic linear damage methodology for small aircraft, Journal of Aircraft 6: 2090-2106. http://dx.doi.org/10.2514/1.C031463

Wahab, M. S.; Paramonov, Yu. M. 2004. The influence of corrosion on reliability and inspection program for fatigueprone airframe structures, Aviation 8(3): 10-17. 